\title{
EMPOWER THE STUDENT, LIBERATE THE PROFESSOR: SELF-ASSESSMENT BY COMPARATIVE ANALYSIS
}

Joi Montiel* $^{*}$

\section{INTRODUCTION}

When Professor John A. Lynch, Jr. returned to the legal writing classroom after years in the doctrinal classroom, he found it to be quite different than it had been decades before. During his reprieve, legal writing pedagogy had significantly changed and the demands on legal writing professors had as well. ${ }^{1}$ The American Bar Association standards for law school accreditation require that students receive substantial instruction in writing in the legal context, which must include "at least one rigorous writing experience in the first year." "Whether a legal writing course satisfies the ABA's "rigorous" requirement depends upon "the opportunities a student has to meet with a writing instructor for purposes of individualized assessment of the student's written products; the number of drafts that a student must produce of any writing project; and the form of assessment used by the writing instructor." 3

In compliance with the standard and in furtherance of pedagogical goals, the legal writing professoriate has embraced "a labor-intensive methodology that stresses individual interaction with students . ..." As Professor Lynch explained, the legal writing professor's review of student drafts and individual student conferences, which are part and parcel of the typical first-year ABA-required rigorous writing experience, threaten the

* Associate Professor of Law, Director of Legal Writing Program, Faulkner University, Jones School of Law. The author would like to thank Faulkner University, Jones School of Law, for providing a grant to support this project and Research and Writing Associate Professor of Law Eric P. Voigt for his feedback.

1. John A. Lynch, Jr., The New Legal Writing Pedagogy: Is Our Pride and Joy a Hobble?, 61 J. LEGAL EDuc. 231, 231 (2011) [hereinafter The New Legal Writing Pedagogy]; see also John A. Lynch, Jr., Teaching Legal Writing After A Thirty-Year Respite: No Country for Old Men?, 38 CAP. U. L. REV. 1, 4-5 (2009) [hereinafter Teaching Legal Writing].

2. AM. BAR Ass'N, ABA STANDARDS: 2014-2015 StANDARDS AND RULES OF PROCEDURE FOR APPROVAL OF LAW SCHOOLS ch. 3 (2015), available at http://www.americanbar.org/ content/dam/aba/publications/misc/legal_education/Standards/2014_2015_aba_standards_chapter 3. authcheckdam.pdf.

3. Id. at Interpretation 302-1.

4. Lynch, Jr., The New Legal Writing Pedagogy, supra note 1. 
professional well being of conscientious legal writing professors. ${ }^{5}$ And "one must hope that virtue is its own reward." ${ }^{\circ}$ Lynch asked if there is anything we can do to "make it better" for law professors.

At the same time, others challenge law professors to "make it better" for the law students. More specifically, law professors are asked to teach law students to be "self-regulated learners" in order to prepare them for the practice of law, where they will have to learn on their own without the benefit of professor feedback. ${ }^{8}$ In that vein, many have called for law professors to formatively assess student learning - to intervene as the learning process is occurring rather than merely assessing whether a student has learned at the end of a course. ${ }^{9}$ Law professors are thus asked to implement strategies to improve a student's ability to evaluate his own learning during the learning process and to provide more opportunities for feedback that are directed to a student's learning process in addition to his final work product. ${ }^{10}$

However, use of formative assessment can be perceived as a burden on professors in large doctrinal courses ${ }^{11}$ and increased number of formative assessments may be a burden on legal writing professors, ${ }^{12}$ who are already familiar with formative assessment. Also, while a legal writing professor can

5. Id. at 237 ("The new pedagogy increases professors' workload enormously by requiring review of preliminary drafts of student work and requiring that a professor spend many hours in individual conferences with students. These duties create a crushing workload for any conscientious legal writing teacher and interferes with the ability of those instructors to produce scholarship, an essential element of the AALS understanding of a law professor's duties.").

6. Id. at 232 (arguing that legal writing professors are the most overworked, underpaid, and underappreciated class of the legal academicians).

7. Id.

8. E.g., Roy Stuckey et Al., Best Practices for Legal Education: A Vision 91 (2007) [hereinafter Best Practices]; William M. Sullivan et al., Educating LaWyers: PREPARATION FOR THE PROFESSION OF LAW 1-5 (2007) [hereinafter CARNEGIE REPORT]; see generally Michael Hunter Schwartz, Teaching Law Students to be Self-Regulated Learners, 2003 MiCH. ST. DCL L. REV. 447.

9. STUCKEY ET AL., supra note 8, at 190-91; see also SULLIVAN ET AL., supra note 8, at 164-67; Michael Hunter Schwartz et al., Teaching Law by Design: Engaging Students From THE SYLLABUS TO THE FINAL EXAM 135-37 (2009) (students believe that they could perform better with a higher quantity and quality of assessment); Carol Springer Sargent \& Andrea A. Curcio, Empirical Evidence that Formative Assessments Improve Final Exams, 61 J. LEGAL EdUC. 379, 380 (2012).

10. E.g., Cassandra L. Hill, The Elephant in the Law School Assessment Room: The Role of Student Responsibility and Motivating Our Students to Learn, 56 How. L.J. 447, 451 (2013) ("law professors and law schools must do more to effectively assess students' responsibility for, and contributions to, their own learning, development, and eventual mastery of substantive law, lawyering skills, and ethical considerations"); Elizabeth M. Bloom, Teaching Law Students to Teach Themselves: Using Lessons from Educational Psychology to Shape Self-Regulated Learners, 59 WAYNE L. REV. 311, 313 (2013); Shailini Jandial George, Teaching the Smartphone Generation: How Cognitive Science Can Improve Learning in Law School, 66 ME. L. REV. 163, 181 (2013) (" $[E]$ ncouraging or teaching students to learn about their own metacognition would be an excellent addition to the first year curriculum.").

11. Sargent \& Curcio, supra note 9, at 380 .

12. See Lynch, Jr., The New Legal Pedagogy, supra note 1. 
assess a student's final product, a legal memo for example, and determine whether desired learning outcomes were met, it is more difficult for the legal writing professor to evaluate the processes that the student used to produce that final product. ${ }^{13}$ But, as the "new" legal writing professoriate has well established, it is critical that legal writing professors intervene in the writing process, not merely correct mistakes that have already been made, to maximize student learning. ${ }^{14}$

This Article proposes a method of formative assessment that requires students to self-regulate their learning and relieves the legal writing professor of our usual labor-intensive assessment practices without reducing the "rigor" of an existing legal writing program and thus threatening its compliance with Interpretation 302-1. ${ }^{15}$ We have called this method "SelfAssessment by Comparative Analysis."16 In short, Self-Assessment by Comparative Analysis requires a student to compare his own work to the work of an "expert" on the same project, analyze the differences, and identify what he needs to improve and how he will improve it, focusing on both his product and his process.

Self-Assessment by Comparative Analysis is less burdensome on the legal writing professor than more direct means of formative assessment, such as individual student conferences and detailed critiques. It offers a corresponding benefit to the student: Self-Assessment by Comparative Analysis provides the law student a tool with which to self-regulate and make adjustments for future legal writing projects. Self-Assessment encourages the student to reflect on, monitor, and adjust his own process, requiring him to self-regulate his learning, as he will need to do in practice.

Although this Article focuses on legal writing courses, the usefulness of the Self-Assessment by Comparative Analysis is not confined to the legal

13. Anthony Niedwiecki, Teaching for Lifelong Learning: Improving the Metacognitive Skills of Law Students Through More Effective Formative Assessment Techniques, 40 CAP. U. L. REV. 149, 182 (2012) ("Without understanding the internal thinking of the students, the professor is unable to correct any process errors.").

14. E.g., Ellie Margolis \& Susan L. DeJarnatt, Moving Beyond Product to Process: Building a Better LRW Program, 46 SANTA CLARA L. REV. 93, 99 (2005) (describing the new legal writing pedagogy in which "[r]ather than merely correcting papers after they were written, LRW professors began to intervene in the writing process, giving substantial attention to individual students' drafts through critiques and conferences on work in progress.").

15. See supra note 3 .

16. Similar approaches have been cursorily referenced elsewhere. See, e.g., GERALD HESS ET AL., TECHNIQUES FOR TEACHING LAW II 184 (2011). One suggestion for providing feedback on writing exercises is the following:

After students individually prepare a writing assignment, give them an answer sheet or drafted answer (yours or a previous student's) in class or post it online. Walk though the answer sheet or give students time to read the answer sheet or samples. Ask students to compare it to the assignment they wrote.

Id. See also Sargent \& Curcio, supra note 9, at 380 (describing self-reflective exercises in doctrinal classes related to students' mid-term exam performance). 
writing classroom. While multiple formative assessments may be burdensome, ${ }^{17}$ a professor teaching a doctrinal class of even a hundred students could provide an effective formative assessment to all of his students by requiring Self-Assessment by Comparative Analysis, that is, by providing a model answer after a mid-term exam along with a Self-Assessment Assignment requiring the student to compare his own work to the model answer, analyze the differences, and identify the causes of his shortcomings. ${ }^{18}$

Students in my legal writing course have discovered for themselves, through Self-Assessment by Comparative Analysis that, on the next legal writing assignment, they need to, for example, (1) read cases more carefully; (2) outline before they write; (3) allow more time for correcting citation before the assignment is due; and (4) spend more time thinking before writing. By discovering these issues through self-assessment, as opposed to being told by their professor, students are more likely to transfer what they learned to other law school classes, the bar exam, and law practice. The ability to learn from feedback and apply this new knowledge to future learning - metacognition - is necessary for a law student to become a selfregulated learner.

Part II of this Article provides an overview of Self-Assessment by Comparative Analysis and provides a few comments from students describing their reception to the concept. In Part III, the Article explains how Self-Assessment by Comparative Analysis liberates professors and empowers students. Part IV explains the self-regulated learning cycle and demonstrates that Self-Assessment by Comparative Analysis teaches students to be self-regulated learners. In Part V, I set out examples of specific tasks required of students in performing Self-Assessment by Comparative Analysis, which can be modified in unlimited ways to accomplish a variety of learning objectives. Part VI responds to the potential objections to SelfAssessment by Comparative Analysis as relying on a sample and as a form of feedback.

17. Sargent \& Curcio, supra note 9, at 389 ("[G]rading multiple [formative] assessments may not be realistic given professors' other commitments."); Niedwiecki, supra note 13, at 174 (noting large size of doctrinal classes as a factor making it difficult to incorporate formative assessments into law school classes, in addition to other demands on professors' time such as service and scholarship requirements).

18. See Sargent \& Curcio, supra note 9, at 389 (describing self-reflective exercises in doctrinal classes related to students' mid-term exam performance); see generally Roberto L. Corrada, Formative Assessment in Doctrinal Classes: Rethinking Grade Appeals, 63 J. Legal Educ. 317 (2013) (describing an innovative method of incorporating formative assessment into a doctrinal course through appeals of midterm exam grades). 


\section{AN OVERVIEW OF SELF-ASSESSMENT BY COMPARATIVE ANALYSIS AND WHAT STUDENTS THINK ABOUT IT}

Self-Assessment by Comparative Analysis requires a student to compare his work to the work of an "expert" on the same project. The student analyzes how his work compares to the expert's work and verbalizes what he needs to improve and how he will improve it. It requires him to focus on how he can improve not only the product, but also the process he used to produce the product. It requires him to reflect on how he worked on the legal writing assignment that is the subject of the assessment, and to put in writing what he knows he will need to do differently in order to improve on the next legal writing assignment.

More specifically, when we, the professors in our legal writing program, create the legal writing assignment that will be the subject of SelfAssessment by Comparative Analysis, we also create a "good memo"-a memo that exemplifies the achievement of all of the learning objectives for the legal writing assignment. ${ }^{19}$ After all students have submitted their final drafts of the memos, we release the "good memo" and a lengthy "SelfAssessment Assignment" that is customized for the particular memo problem. The Self-Assessment Assignment methodically guides the student through the process of evaluating his own final memo and critiquing it in comparison to the "good memo," much in the way that a legal writing professor would evaluate the student's memo in comparison to his or her expectations for the assignment.

The overall idea is that, rather than the professor providing feedback as to whether the student met or fell short of expectations for the assignment, the student himself can evaluate whether he met or fell short of the expectations. Those expectations are concretely set out for the student in the form of the "good memo." Furthermore, the Self-Assessment Assignment asks questions about the student's process, ${ }^{20}$ requiring the student to reflect on his process and providing the professor with insight into the student's thought process and work habits that would not be apparent from the professor's review of the student's memo alone. ${ }^{21}$

While preparing the "good memo" and the Self-Assessment Assignment requires a bit more work by the professors before the semester

19. I have chosen the term "good" memo rather than "model" memo or "sample" memo in an effort to avoid the problem of students viewing a "model" or "sample" memo as a template to "go by" for composing all future memos. See Miriam E. Felsenburg \& Laura P. Graham, A Better Beginning: Why and How to Help Novice Legal Writers Build a Solid Foundation by Shifting Their Focus from Product to Process, 24 Regent U. L. Rev. 83, 98 (2012) (addressing dangers in using samples).

20. Niedwiecki, supra note 13, at 182 (suggesting that professors ask process questions as part of an assignment).

21. Id. (stating that incorporating self-assessments into a course is the "most effective way" to understand student thinking). 
begins, ${ }^{22}$ we spend significantly less time and energy critiquing memos during the semester. Conversely, the students continue to engage in the learning process after they have submitted a final draft of the ungraded memo, rather than mentally closing the chapter on that assignment.

While students do complain that the exercise requires a lot of time and effort, they also admit that they learn from it. Students have indicated in the Self-Assessment Assignment itself how helpful it can be. When asked whether he understood the weaknesses of his earlier draft from the feedback I had provided, but before he completed the Self-Assessment Assignment, one student wrote:

Yes, but not to this extent. I do not think it is possible for any professor to spend enough personal time with a student that they can demonstrate the weaknesses that have been exposed by this assignment. I do believe my professor's feedback was pivotal in the development of my skills, but without this assignment I'd still be somewhat "in the dark."

Another student comment demonstrates how students are empowered by the exercise:

I have learned a tremendous amount. Light bulbs have been going off the entire section. In my memo, my rules, support, and conclusions were all over the place. This section has really shown me exactly how I need to attack my final memo. I'll be honest: while doing this section, I started to become very unsure of my writing. I really couldn't believe how terrible my memo was. However, the work that is being put into this evaluation is really going to pay off. My structure, organization, and rule statements are all going to change drastically.

Students appreciate "seeing the ball"23 and appreciate how much they learn from the Self-Assessment Assignment. Their acknowledgement that they performed well or performed poorly on the legal memo, and that they learned what to do in the future from the Self-Assessment Assignment, demonstrates the effectiveness of Self-Assessment by Comparative Analysis. One student actually thanked me for the exercise:

This assignment revealed all of the tiny details that, if you think about it, really add up to being all of your paper. Therefore, legal writing is

22. The time involved in producing good sample writing is cited as one reason professors are reluctant to use samples. Christine N. Coughlin et al., See One, Do One, Teach One: Dissecting the Use of Medical Education's Signature Pedagogy in the Law School Curriculum, 26 GA. ST. U. L. REV. 361, 392 (2010) ("Professors may also omit samples because finding a comprehensive 'good' sample takes so much time and effort, usually requiring the professor to draft such a sample.").

23. See generally Sophie M. Sparrow, Describing the Ball: Improve Teaching by Using RubricsExplicit Grading Criteria, 2004 Mich. ST. L. REV. 1. 
comprised of detail, detail, detail. I have now been warned of this. Thanks for this.

\section{AS A FORMATIVE ASSESSMENT, SELF-ASSESSMENT BY COMPARATIVE ANALYSIS LIBERATES LAW PROFESSORS AND EMPOWERS STUDENTS}

While summative assessment, such as a final exam at the end of a course, evaluates whether a student has satisfied the learning outcomes of a course, often resulting in a grade, formative assessment provides feedback about student learning during the learning process. ${ }^{24}$ Formative assessment provides information as to whether students are learning and what adjustments need to be made to the learning and teaching process so that the student can later achieve the desired learning outcomes of a course. ${ }^{25}$ Formative assessment has been defined as "anything the students and teachers do in the learning process that can provide information on ways to adjust teaching and learning." 26 If assessment comes too late, such as by way of final exam only, the opportunity for a student to improve his performance is foregone. For this reason, many have called for increased use of formative assessment in law schools. ${ }^{27}$

However, increasing the number of formative assessments within a legal writing course may burden legal writing professors, who are already familiar with formative assessment. ${ }^{28}$ Self-Assessment by Comparative Analysis, however, provides the benefit of a formative assessment to the student without placing a corresponding burden on the professor. In fact, using Self-Assessment by Comparative Analysis will save legal writing professors time.

Specifically, Self-Assessment by Comparative Analysis is intended to be implemented in lieu of the legal writing professor critically evaluating forty or fifty student memos during the semester. Our fall semester first-year legal writing course is the typical legal writing course:

[Students] begin the semester by drafting a single legal argument that relies on a statute or one or two precedential cases or both. The next major assignment may involve a closed universe of research with multiple cases

24. Niedwiecki, supra note 13, at 172.

25. Id.

26. Id. at 175. Both the student and the teacher can adjust if formative assessments reveal that improvements are needed to enhance learning on the part of the student and teaching on the part of the professor.

27. E.g., STUCKey ET AL., supra note 8, at 190-01; Sullivan ET AL., supra note 8, at 188-89; Schwartz, supra note 8, at 154-58.

28. See Lisa T. McElroy et al., The Carnegie Report and Legal Writing: Does the Report Go Far Enough?, 17 J. LEGAL WRITING INST. 279, 319 (2011). 
requiring the student to synthesize the rule and construct counter arguments. A third assignment may involve an open universe of research requiring the students to be able to locate, cull through and weigh relevant authorities, synthesize an appropriate rule, and write about several different legal issues. $^{29}$

We use Self-Assessment by Comparative Analysis in connection with the second major writing assignment. Before we incorporated SelfAssessment by Comparative Analysis into our legal writing program, the process associated with the second major writing assignment was as follows: (1) students submit their first drafts; (2) the professor reviews and comments on the first drafts, then returns the reviewed drafts to the students; (3) the students study and learn from the professor's comments; (4) the students conference with their professor to discuss their questions about the professor's comments; (5) the students submit second drafts; (6) the professor reviews and comments on the students' second drafts, then returns them to the students; and (7) some students perhaps study the professor's comments with the intention of using the feedback to improve on the next assignment.

Under the former and more traditional approach, assuming that a professor expended one hour reviewing each memo and assuming a load of forty students in a semester, the professor would invest forty hours of time at step 6. And in our program, that forty hours was expended during one week so that the student feedback was timely. ${ }^{30}$ In other words, that sixth step was quite a burden on the professors. Yet, the students had the option of reviewing or not reviewing the professor's comments on their second drafts. So, the students could have expended no time or effort learning from reflecting on their second drafts. That forty hours of grading that each professor invested could well have been in vain. ${ }^{31}$

In contrast, by using Self-Assessment by Comparative Analysis, we have eliminated the sixth step for the professors. Instead of that forty hours of review in one week, we need only prepare a "good memo"32 and the Self-

29. Id. at 318-19.

30. See HESS ET AL., supra note 16, at 265 (noting that timeliness of feedback is critical to feedback being effective).

31. At least with respect to some students. In an informal survey, some students have informed us that they would have reviewed their professors' comments even if they had not been required to; however, that is doubtful except for perhaps the most dedicated students. E.g., Corrada, supra note 18, at 319-20 (observing that students forego the "excellent learning opportunity" of reviewing midterms with their professor); see also Anne M. Enquist, Unlocking the Secrets of Highly Successful Legal Writing Students, 82 ST. JOHN's L. REV. 609, 654 (2008) (“[A]lthough Professor Lee had added a comment on her critique of Marie's pre-trial brief that she (Marie) should consider coming in for an office conference to discuss the pre-trial brief, Marie did not take her up on the offer.").

32. See supra note 19. 
Assessment Assignment. And those can be prepared by one professor in the program, rather than all of them, and they be completed before the semester begins. Moreover, they can be reused in later semesters.

During the semester, the new sixth, seventh, and eighth steps are: (6) the professor releases the already-prepared "good memo" and the SelfAssessment Assignment customized for the particular problem; (7) all students review the good memo, re-assess their own memos, and analyze the differences; and (8) all students submit their Self-Assessment Assignment. Thus, all students are required to expend approximately eight hours learning from reflecting on their second drafts. They are not given a realistic option of foregoing the opportunity for learning, as they were under the former approach.

We allow the students two or three weeks to complete the SelfAssessment Assignment, and we encourage students to complete the exercise in several shorter periods of time, rather than fewer long periods. The SelfEvaluation Worksheet contains space for the student to "check off" each completed item so that they can track their progress. When the assignment is due, each student submits three documents: (1) the final draft of his own memo, which will show highlighting and marking as a result of the student's self-assessment; (2) a copy of the "good memo," which will also show significant highlighting and marking required by the exercise; and (3) the completed Self-Assessment Assignment which contains the student's written analytical comparison. So that students will be motivated to put a good faith effort into the exercise, their good faith effort at a thorough and objective Self-Assessment is five percent of their final grade in the course. Students submit the Self-Assessment Assignment to the professor when they come in for a conference on the first draft of their third and final memo. That provides an opportunity for the professor to discuss with the students what they learned from the Self-Assessment Assignment.

While Self-Assessment by Comparative Analysis preserves the professors' time and energy that might otherwise be wasted, it is worth considering what knowledge of the students' progress we forego by not reviewing our students' second drafts. Certainly, we forego some basic knowledge about the students' final products. In return, however, the students are gaining knowledge about their final products by comparing them to the "good memo." Moreover, both the students and the professors are gaining knowledge about the students' process. The student gains that knowledge through the Self-Assessment Assignment itself, and the professors gain that knowledge by reviewing the student's Self-Assessment Assignment. A student may be forced to discover, and reveal to the professor, that, for example, she failed to appreciate the time necessary for the assignment, failed to carefully review cases before attempting to write, failed to outline before writing, failed to carefully proofread, or failed to take 
advantage of the resources provided. And the student's knowledge about her process, not the professor's knowledge about what the student needs to do to improve, is what is key to the student's ability to transfer what she learns so that he can improve on the next assignment. ${ }^{33}$

The Self-Assessment by Comparative Analysis not only reduces the legal writing professor's time commitment to direct evaluation, ${ }^{34}$ but it is more beneficial to the student because it enhances the student's ability to become a self-regulated learner, the benefits of which are discussed in Section IV below. In addition, it allows for feedback that is timely in a way that would not be possible if a professor were providing individual feedback on each student's memo. ${ }^{35}$

\section{AS A SELF-REGULATED LEARNING TOOL, SELF- ASSESSMENT BY COMPARATIVE ANALYSIS ENHANCES TRANSFER OF LEARNED SKILLS}

"Legal education is necessarily continuous over a lawyer's career, so the lawyer must be equipped to learn autonomously." 36 In other words, a successful lawyer must be a self-regulated learner. ${ }^{37}$ By self-regulating one's learning, the skills learned can be internalized and thus are more likely to be transferred to new situations, ${ }^{38}$ such as another law school course, the bar exam, or the practice of law.

The idea is that this heightened awareness will help the brain to encode new knowledge within the full spectrum of classroom, conceptual, and emotional experiences, making it easier to recall and adapt the information later. Theorists also believe that this mindfulness during the learning process will help the learner to see similarities between contexts, allowing her existing schema to evolve and encompass new information. When a

33. See infra Part IV (describing how Self-Assessment by Comparative Analysis encourages selfregulated learning and thus enhances transfer of learned skills to new assignments).

34. It can also provide the professor with information regarding the effectiveness of his or her classroom teaching, method of reviewing writing assignments, and conferencing techniques. See infra note 91.

35. See HESS ET AL., supra note 16, at 265 (noting that timeliness of feedback is critical to feedback being effective).

36. Jay Feinman \& Marc Feldman, Pedagogy and Politics, 73 GEO. L. J. 875, 894 (1985) (quoted in Schwartz, supra note 8, at 469); see also Alice M. Thomas, Laying the Foundation for Better Student Learning in the Twenty-First Century: Incorporating an Integrated Theory of Legal Education into Doctrinal Pedagogy, 6 WIDENER L. SYMP. J. 49, 64 n.55 (2000) ("If the student is successful, then learning will occur even in the absence of the teacher as it must within the legal profession.").

37. E.g., Thomas, supra note 36 , at 76 .

38. Niedwiecki, supra note 13, at 182-83. Without self-assessing and internalizing, students may simply look at their "grade" and fail to think about how to correct their mistakes as they move forward to the next writing project. $I d$. 
person's schema adapts to include new information and patterns, it becomes much easier to "connect the dots," cueing latent learning that might be useful to solve a new problem. When educators present material with these strategies, they encourage their students to mindfully encode material in useful patterns or schema, making it easier to recall and use the information later. ${ }^{39}$

Thus, law schools must teach students to self-regulate their learning. ${ }^{40}$ We can begin to do this by providing formative assessments that require students to self-regulate - to learn from feedback and apply what they learn to future learning. ${ }^{41}$ Self-Assessment by Comparative Analysis is one tool ${ }^{42}$ that explicitly encourages and teaches students to be self-regulated learners. Section IV.A. describes the phases of the self-regulated learning cycle, and Section IV.B. demonstrates how Self-Assessment by Comparative Analysis speaks to key phases of the self-regulated learning cycle.

\section{A. The Self-Regulated Learning Cycle}

A student is engaging in self-regulated learning when, for example, she notices that she is having "more trouble learning $\mathrm{A}$ than $\mathrm{B} ;{ }^{43}$ it strikes her

39. Tonya Kowalski, True North: Navigating for the Transfer of Learning in Legal Education, 34 SeattLe U. L. Rev. 51, 73-74 (2010).

40. E.g., SUlLiVAN ET AL., supra note 8, at 173 ("[T] he essential goal of professional schools must be to form practitioners who are aware of what it takes to become competent in their chosen domain and to equip them with the reflective capacity and motivation to pursue genuine expertise. They must become 'metacognitive' about their own learning."); STUCKEY ET AL., supra note 8, at 127 (recommending that law schools "help students improve their self-directed learning skills"); Schwartz, supra note 8, at 468 (citing the MacCrate Report); see also Niedwiecki, supra note 13, at 152 (noting that the CARNEGIE REPORT and BEST PRACTICES highlight the need to prepare law students to be "better prepared for lifelong learning, something that goes to the core of what it means to be a lawyer" and arguing that law schools need to prepare law students to be self-regulated learners because they will be "constant learners in the practice of law"); Felsenburg \& Graham, supra note 19, at 95 (arguing that law students should be encouraged to be more active metacognitive learners); see also Pamela Lysaght \& Christina D. Lockwood, Writing-Across-theLaw School Curriculum: Theoretical Justifications, Curricular Implications, 2 J. Ass'N LEGAL WRITING DIRECTORS 73, 89-90 (2004) ("Because metacognition is a needed skill for a competent new attorney, teachers should encourage students to actively think about their learning process to become proficient at metacognition.").

41. Niedwiecki, supra note 13, at 152 (arguing that professors should use formative assessments to improve metacognitive skills of law students in order to develop students who are more successful at transferring their learning to new and novel situations that they will encounter in law practice).

42. Law professors should use a variety of assessment techniques throughout the semester. Carolyn Grose, Outcomes-Based Education One Course at a Time: My Experiment with Estates and Trusts, 62 J. LeGAL EDUC. 336, 352 (2012).

43. Robin A. Boyle, Employing Active-Learning Techniques and Metacognition in Law School: Shifting Energy from Professor to Student, 81 U. DET. MERCY L. REV. 1, 8 (2003) (citing John H. Flavell, Metacognitive Aspects of Problem Solving, in THE NATURE OF INTELLIGENCE 231 (Lauren B. Resnick ed., 1976)). 
that she should "double-check $\mathrm{C}$ before accepting it as fact," that she "had better make a note of D because [she] may forget it;", 45 she thinks to "ask someone about E to see if [she has] it right." 46

On a deeper level, the self-regulated learning cycle consists of three major phases: ${ }^{47}$ forethought, performance, ${ }^{48}$ and self-reflection. ${ }^{49}$ The forethought phase involves the influential processes and beliefs that exist before the student begins efforts to learn. ${ }^{50}$ The second phase, performance, involves the processes that occur during learning efforts. ${ }^{51}$ The third phase, self-reflection, involves processes that occur after learning efforts have occurred..$^{52}$ The three-phase learning process is cyclical: the self-reflection efforts that occur in the third phase influence the first learning phase, forethought, in subsequent learning efforts. ${ }^{53}$

The Self-Assessment Assignment proposed in this Article addresses primarily the "pivotal" 54 third phase - self-reflection — and its impact on the first phase. ${ }^{55}$ In the remainder of this section, I briefly explain the first phase, forethought, and third phase, self-reflection. In Section IV.B. that follows, I explain how the Self-Assessment Assignment speaks directly to the first and third phases, forethought and self-reflection, and indirectly to the second phase, performance.

The first phase of the self-regulated learning cycle, the forethought phase, involves the influential processes and beliefs that exist before the student begins efforts to learn. ${ }^{56}$ At this stage, among other things, ${ }^{57}$ the student will set goals- she will determine the desired outcomes. ${ }^{58}$ The

44. $I d$.

45. $I d$.

46. Id.

47. Barry J. Zimmerman, Developing Self-Fulfilling Cycles of Academic Regulation: An Analysis of Exemplary Instructional Models, in Self-Regulated Learning: From Teaching to SelfReflective Practice 1 (Dale H. Schunk \& Barry J. Zimmerman eds., 1998). Professor Michael Hunter Schwartz relied on this cyclical phase in arguing that law professors should teach students to be self-regulated learners. See Schwartz, supra note 8, at 454-61. As Professor Schwartz has noted, there are other models of self-regulation although Zimmerman's model is the most often cited one. See id. at 455. In this Article, I rely largely on Schwartz's conception of Zimmerman's model.

48. This is also called "volitional control." Zimmerman, supra note 47, at 2.

49. Id.

50. Id.

51. Id.

52. Id.

53. Id.

54. Id. at 5 .

55. For a more in depth explanation of the self-regulated learning process in the law school context, see Schwartz, supra note 8, at 454-61.

56. Zimmerman, supra note 47, at 2-3; Schwartz, supra note 8, at 455-58 (citing Zimmerman, supra note 47).

57. See supra note 48 .

58. Zimmerman, supra note 47, at 2-3; see also Schwartz, supra note 8, at 455-58 (citing Zimmerman, supra note 47). 
student will also assess her efficacy for accomplishing the goal-she will estimate her ability to accomplish the task. ${ }^{59}$ The student will also engage in strategic planning - she will select the learning strategies that are likely to result in the desired outcomes. ${ }^{60}$

The third phase of the self-regulated learning cycle, the reflection phase, impacts future learning. ${ }^{61}$ " $[\mathrm{I}] \mathrm{t}$ is backward-looking in the sense that the student reflects on what she just did and how effective it was." ${ }^{92}$ In addition, "it is forward-looking in the sense that the student considers the implications of her experience for future learning activities." ${ }^{63}$ In other words, it impacts the forethought phase of future learning activities by impacting the selection of learning strategies in those future activities.

The reflection phase includes four aspects: self-evaluation, attribution, self-reaction, and adaption. Self-evaluation involves comparing one's performance with "some sort of standard or goal." 64 Having compared one's own work to that of the standard or goal, the student next makes "attributions" about the causes of the results of her comparison; the student determines why she performed well or underperformed. ${ }^{65}$ Attributions are "pivotal" ${ }^{66}$ according to Barry J. Zimmerman, the leading authority in the area of self-regulated learning. ${ }^{67}$

Attributions are pivotal because they impact two aspects of the selfreflected learning process that are critical to continued learning. First, attributions impact a student's self-reaction. ${ }^{68}$ If a student fails to meet the desired outcome for the learning task, the question is whether the poor performance is due to the student's limited ability or to the student's poor effort. ${ }^{69}$ If the student attributes poor performance to limited ability, the student will "give up" on trying to improve. ${ }^{70}$ In contrast, if the student can attribute poor performance to poor effort, be it poor quality or poor quantity,

59. Zimmerman, supra note 47, at 2-3; Schwartz, supra note 8, at 455-8 (citing Zimmerman, supra note 47 , and others).

60. Zimmerman, supra note 47, at 2-3; Schwartz, supra note 8, at 455-58 (citing Zimmerman, supra note 47 , and others).

61. Zimmerman, supra note 47, at 4-5; Schwartz, supra note 8, 460-61 (citing Zimmerman, supra note 47).

62. Schwartz, supra note 8 , at 460

63. Id. at 461 .

64. Zimmerman, supra note 47 , at 2-3.

65. Id. at 5; Schwartz, supra note 8, at 461 (citing Zimmerman, supra note 47).

66. Zimmerman, supra note 47 , at 5 .

67. Schwartz, supra note 8 , at 452 .

68. Zimmerman, supra note 47, at 5; Schwartz, supra note 8, at 461 (citing Zimmerman, supra note 47).

69. Zimmerman, supra note 47, at 5; Schwartz, supra note 8, at 461 (citing Zimmerman, supra note 47).

70. Zimmerman, supra note 47, at 5; Schwartz, supra note 8, at 461 (citing Zimmerman, supra note 47). 
he can adapt appropriately. ${ }^{71}$ Adaptation is the second important aspect of the self-reflective learning process impacted by attribution. ${ }^{72}$ Attribution assists in identifying the source of learning errors so that the student can adapt performance on the next learning task. ${ }^{73}$ Thus, this third, reflective, phase of the self-regulated learning process, predictably, influences the first phase, forethought, in a subsequent learning project. ${ }^{74}$ For example, a student may attribute his low level of performance to poor time management; thus, the student can adapt as he begins the first phase of the next writing project by allocating more time.

\section{B. Self-Assessment by Comparative Analysis Requires the Student to Engage in Self-Regulated Learning}

Self-Assessment by Comparative Analysis requires a student to comparatively analyze how his work compares to the work of an "expert" on the same project and to verbalize what he needs to improve and how he will improve it. It requires him to focus on how he can improve not only the product, but also the process he used to produce the product. It requires him to reflect on how he worked on the legal writing assignment that is the subject of the assessment, and to put in writing what he knows he will need to do differently in order to improve on the next legal writing assignment. Thus, Self-Assessment by Comparative Analysis addresses primarily the "pivotal"75 third phase-self-regulation — and its impact on the first phase. ${ }^{76}$

First, the Self-Assessment Assignment allows the student to see the desired outcome, an aspect of the forethought phase. It requires the student to compare his performance with "some sort of standard or goal" - the "good memo" written by the legal writing professor. A new legal writing student has little appreciation or understanding for what a "good" piece of legal writing is. ${ }^{77}$ Providing the student with a "good memo" gives him some

71. Zimmerman, supra note 47, at 5; Schwartz, supra note 8, at 461 (citing Zimmerman, supra note 47).

72. Zimmerman, supra note 47, at 5; Schwartz, supra note 8, at 461 (citing Zimmerman, supra note 47).

73. Zimmerman, supra note 47, at 5; Schwartz, supra note 8, at 461 (citing Zimmerman, supra note 47).

74. The CARNEGIE REPORT addressed this cycle in the context of legal writing instruction. SULLIVAN ET AL., supra note 8, at 109-10. (Metacognition “turns the student's activity back on itself in order to produce awareness in the student of what is being learned - a 'second order' or reflective awareness; the process is then reiterated, with gradually more difficult and complex asks, toward the aim of improved competence in writing, [among other things, depending on the aspect of practice being learned].").

75. Boyle, supra note 43 , at 5 .

76. For a more in depth explanation of the self-regulated learning process in the law school context, see Schwartz, supra note 8, at 454-61.

77. Felsenburg \& Graham, supra note 19, at 97-99. 
vision of the desired outcome. The "good memo" is a clear, accurate picture of the professor's expectations for the assignment. ${ }^{78}$ It is the standard against which the professor would evaluate the student's memo if the professor were evaluating the memo. By comparing his own memo to the "good memo" prepared by his professor, the student receives feedback from the professor in terms of the professor's expectations. The exercise does not allow for general comparisons. ${ }^{79}$ Instead, a variety of specific self-reflective questions are asked requiring the student to examine where he may have underperformed on multiple levels, including large-scale organization, small-scale organization, choice of authority, and depth of analysis. By comparing his own memo to the model prepared by his professor, the student can self-assess whether he met or fell short of those expectations.

In addition to requiring him to compare his memo to the "good memo"- the Self-Assessment Assignment requires the student to make "attributions" about the causes of the results of his comparison; the student is asked to determine why he performed well or underperformed. The student is asked where the memo fell short of (or met) expectations in a variety of areas including large-scale organization, small-scale organization, choice of authority, and depth of analysis. Having identified those shortcomings, the student is asked to explain why he underperformed. The exercise asks the student to explain why he made the choices he made that differed from the choices made by the writer of the "good memo." For example, the student must explain why he did not include certain relevant facts as he applied the law and to contemplate why the writer of the "good memo" did include those relevant facts.

The student is also asked to identify the weaknesses in his process that caused the weaknesses in his product. A student may enter a first year legal writing class with the expectation that he can write the legal memo a night or two before its due date and still perform well. He expects that because he has learned that in undergraduate studies. ${ }^{80} \mathrm{He}$ may also expect the law to be a subject area that he will be able to read, memorize, and recall, as in other subject areas. ${ }^{81}$ However, his beliefs are erroneous. He is likely to discover his error when comparing his own work to the "good memo."

A very simple example of attributing a weakness in the product to a weakness in the process would be a student recognizing that he had many proofreading errors in his final draft and, thus, attributing that weakness to a

78. It must be, or else the purpose of the "good memo" is not met. See Niedwiecki, supra note 13, at 178 (noting the importance that the student's perception of the goals of an assignment or course be the same as the professor's).

79. See infra Part V. Setting out specific requirements of the Self-Assessment Assignment.

80. Felsenburg \& Graham, supra note 19, at 88-89 (explaining the study of first-year law students at Wake Forest that revealed that most students come to law school overestimating their writing abilities).

81. Id. at 89 . 
failure to allocate sufficient time to proofread. Or, he might discover that he should proofread a printed copy of the document instead of an electronic version in order to catch more proofreading errors. Similarly, a student might recognize that he failed to fully explain the complexities of a case that was discussed in both the "good memo" and the student's memo. He might attribute that failure to his erroneous assumption that such a deep level of analysis was not necessary, or he might attribute it to a failure to read the case closely enough. New legal writing students are likely to underestimate the amount of time and effort that will be required to produce a legal memo that achieves the desired level. ${ }^{82}$ The Self-Assessment Assignment can serve as an early "wake up call" 83 for these students.

The Self-Assessment Assignment will also impact the student's selfefficacy. Students often indicate that they discover, after reading the "good memo," that they "knew" or "thought about" the analysis that they read in the "good memo," but they simply did not see the need to fully explain all of that thought process - the analysis - in the legal memo. Thus, the "good memo" can serve to increase a student's self-efficacy by showing the student that, even if he did not perform at the level of the "good memo" writer on this particular legal writing assignment, he has the ability to perform at that level, or at least a higher level, on the next legal writing assignment. ${ }^{84}$ When a student has early information about his shortcomings, and knows that he has the opportunity to make adjustments and improve, he may be inspired to increase his efforts. ${ }^{85}$ By requiring a student to focus on the quantity and quality of his efforts, and prompting him with useful questions, the student can attribute underperformance to poor strategy selection rather than to a lack of personal ability. Thus, the student will be encouraged that he can perform better on the next learning task.

To explicitly require the student to consider how he can perform better on the next learning task, the Self-Assessment Assignment requires the student to explain how he will avoid in future writing projects the problems that he identified at the attribution stage. ${ }^{86}$ The student is empowered ${ }^{87}$ by

82. See Felsenburg \& Graham, supra note 19.

83. While the adaption process requires many cycles, more cycles are possible by utilizing selfassessment than would be by a professor providing direct feedback. See Schwartz, supra note 8, at 451.

84. Conversely, self-efficacy is also addressed by providing the sample memo to the over-confident student. See Zimmerman, supra note 47, at 9 (“[M] any students fail to self-monitor their learning progress accurately and tend to overestimate their level of success," which leads to "misplaced optimism, substantial understudying, and, ultimately, low test scores.").

85. Sargent \& Curcio, supra note 9, at 382.

86. Niedwiecki, supra note 13, at 183. In a similar vein, the Self-Assessment Assignment also has the benefit of avoiding the phenomena of student dependency on the professor. See id. at 180-81.

87. Miriam E. Felsenburg \& Laura P. Graham, Beginning Legal Writers in their Own Words: Why the First Weeks of Legal Writing are So Tough and What We Can Do About It, 16 J. LEGAL WRITING INST. 223, 295 (2010) (summarizing scholarship on metacognition as explaining that "the student 
knowing that he will begin the next learning task armed with a better strategy than he had when he began the previous task. By self-assessing, rather than by being assessed by a professor, the student can internalize ${ }^{88}$ the skills learned; thus, the student is more likely to transfer those skills to new writing assignments in the legal writing course or even to different courses. ${ }^{89}$

Students should be reminded later in the course of the discoveries they made while working through the Self-Assessment Assignment. In this way, the Self-Assessment Assignment addresses the second phase of the selfregulated learning cycle. Students are prompted later in the semester, and in the following semester, to evaluate whether they are actually implementing new strategies to replace the old strategies that they previously identified as ineffective. For example, the Self-Assessment Assignment asks questions such as: "If you could write this memorandum again, what would you do that is procedurally different?" Students provide answers such as: "I will seek help from the professor more often" or "I will spend more time outlining before writing." We keep copies of those answers and return them to the students at strategic points later in the semester, and even in the following semester, with a note asking the student to consider whether he is actually implementing the new strategies.

\section{SPECIFIC REQUIREMENTS OF THE SELF-ASSESSMENT ASSIGNMENT}

The Self-Assessment Assignment guides the student in the process of evaluating his own final memo and critiquing it in comparison to the "good memo." Below are some specific tasks that we have required in the SelfAssessment Assignment. These tasks can be modified and implemented in an unlimited number of ways to suit a professor's learning objectives for a specific assignment.

A. Pre- and Post-Exercise Assessment of Whether Objectives Were Met to Gauge Accuracy in Self-Monitoring

The Self-Assessment Assignment provides the student several opportunities to self-assess. The Self-Assessment Assignment requires the student to first evaluate his memorandum holistically. The student is asked

himself must be empowered to take charge of his own learning"); Schwartz, supra note 8, at 505 (reporting that five or six of the students who had taken Professor Schwartz's self-regulated learning course described the course as an "empowering, life-changing experience").

88. Niedwiecki, supra note 13 , at 182 . Without self-assessing and internalizing, students may simply look at their "grade" and fail to think about how to correct their mistakes as they move forward to the next writing project. See id. at 183.

89. Schwartz, supra note 8, at 475; Niedwiecki, supra note 13, at 156. 
on the first page of the assignment to rate his own memo as (1) unacceptable at this point in the semester, (2) acceptable at this point in the semester, or (3) showing significant improvement from the previous draft. After he has completed the Self-Assessment Assignment, he is asked to reconsider the initially assigned rating. He must then explain why his rating changed or remained the same. This process helps students develop accuracy in selfmonitoring. ${ }^{90}$

\section{B. Reflection on Earlier Professor Feedback to Encourage Use of Resources in Future Assignments}

The Self-Assessment Assignment requires the student to reflect on whether he is learning from the direct feedback that the professor has previously provided him. At the beginning of the exercise, the student is prompted as follows:

Think about the written comments that you received from your professor on your previous draft of this memo. What two or three comments were most helpful in revising the memo? Which two or three comments were least helpful? Please be specific and state reasons why the comments were helpful or not helpful.

This line of questioning is designed to prompt students to reconsider whether they are actually using the direct feedback that the professor has given them or realize where they have failed to do so. ${ }^{91}$

\section{Direct Comparison to Good Memo to Promote Understanding of Objectives}

\section{Self-evaluation of small-scale structure (CREAC parts)}

The legal problem that is resolved by the "good memo" and that is the subject of the Self-Assessment Assignment calls for a discussion of multiple issues. The "good memo" discusses each issue separately and discusses each

90. See Schwartz, supra note 8, at 489 (citing Deborah L. Butler \& Philip H. Winne, Feedback and Self-Regulated Learning: A Theoretical Synthesis, 65 REV. EDUC. RES. 245, 253 (1995)) (explaining that student journaling about the accuracy of their predictions helps students develop accuracy in their self-monitoring because they are receiving information about the practical effects of the learning strategies they are using).

91. These answers might also reveal where the professor has failed to provide clear feedback. See Niedwiecki, supra note 13, at 173 (noting that another important goal of assessment is evaluating the school's curriculum and course instructions to determine if there are ways to improve student performance and learning). Thus, the student's work on the Self-Assessment Assignment can also benefit the professor by providing clues as to whether the teacher's method of commenting might need revision. 
issue according to the "CREAC" principles. The depth of each issue's discussion varies.

Showing students that CREACs vary in degrees of depth, although they are consistent in structure, is beneficial. Whereas using the CREAC structure is a cognitive skill, determining when to modify the structure is a metacognitive skill, which requires a more complex thought process. ${ }^{92}$ By using a problem and a good memo that calls for variances among issues, students can see that the structure remains the same even where the analytical content varies. ${ }^{93}$ While they might be otherwise inclined to believe that "CREAC" is a formula in which to "plug" law and fact, they can see that CREACs can — and should - be varied according to what is appropriate for a particular issue. We make explicit in the Self-Assessment Assignment instructions that we want the student to understand that the "good memo" is not a template for future writing projects; instead, it is an example of how one legal writer chose to address the issue. ${ }^{94}$ Students should understand that writers undoubtedly differ in their evaluation of an issue; however, skilled writers employ the same analytical and organizational strategies in writing any memo. The instructions read:

Your audience, a law-trained Reader, expects to see something like this good memo. You are not expected to write a memo that is just like the "good memo" for two main reasons.

First, there are many different ways that this memo could have been written. If ten seasoned lawyers wrote memos analyzing whether [the rule of law covered in the memo is or is not satisfied], each memo would look different from the others in some ways and the predicted outcomes could vary. Nonetheless, there are certain principles that all of those lawyers would likely follow, as you should have; for example, issues are best analyzed one at a time, legal conclusions are reached with syllogistic reasoning, and reasonable counter-arguments must be addressed. Second, you are only halfway through your first semester of law school. In contrast, the writer of the "good memo" is an experienced legal writer.

So that students discover that CREACs may vary in size and depth, students are asked to highlight in designated colors CREAC parts ${ }^{95}$ of the discussion of a single issue on both their own memo and on the "good

92. Id. at 157 .

93. See Coughlin et al., supra note 22, at 386-87.

94. Graham, supra note 19, at 98 (noting that professors must be transparent in providing samples).

95. This idea belongs to Mary Beth Beazley. See Mary Beth Beazley, The Self-Graded Draft: Teaching Students to Revise Using Guided Self-Critique, 3 J. LEGAL WRITING INST. 175, 182-86 (1997) [hereinafter The Self-Graded Draft]; Mary Beth Beazley, Better Writing, and Better Thinking: Using Legal Writing Pedagogy in the "Casebook" Classroom (Without Grading Papers), 10 J. LEGAL WRITING INST. 23, 60-62 (2004) [hereinafter Better Writing]. 
memo." For example, they will highlight rules in green and application in pink.

Students must then list on the Self-Evaluation Worksheet any rules highlighted in the "good memo" that were not included in their own memo. Then, they are asked to explain why they did not include those rules in their own memo. Conversely, they are also asked to list rules highlighted in their own memo that were not included in the "good memo" and to explain why the rules were included in their own memo. In addition to serving the purpose of showing students where they are missing or misconstruing rules, this exercise also serves as encouragement to the students who are successfully using rules in their memos.

\section{Self-evaluation of application of a single issue}

While still focusing on the discussion of a single issue within the memo, students are directed to focus on the Application, which should be highlighted in pink on both the "good memo" and the students' memos. On the "good memo," students underline individual facts about their client's case; circle individual facts of a precedent case; and draw a box around the words indicating comparison between the two such as "like," "similar," and "in contrast." Students are then asked to do the same on their own memo. Next, students determine whether there are underlined words, circled words, or boxed words on their own memo; if not, the student must explain why not. Through this process, students can recognize their failure to make analogies and distinctions between their own case and the precedent cases. One student wrote on his Self-Assessment Assignment, "I realize that would state that the facts of my case are similar to the facts of the precedent case, but I did not specify the facts that I believed were similar because they had been stated earlier. But I need to show exactly how the facts of the two cases are similar."

\section{Self-evaluation of objectivity}

Students are also required to examine whether they objectively evaluated both sides of the issue. Every semester, at least a few students fail to understand that their assignment is to objectively evaluate the possible outcomes rather than to argue in favor of their fictional client until they complete the Self-Assessment Assignment. In the Self-Assessment Assignment, students are asked to list in a table "arguments" presented in their own memo that support the conclusion that that issue would be decided in favor of their client. In a second column of the table, they are asked to list arguments presented in the "good memo" that support the same conclusion. Students should be able to see where they failed to identify valid arguments 
to be made for that position, or where they identified arguments that were perhaps questionable.

On a second table, students are instructed to list "arguments" presented in their own memo that support the conclusion that the issue would be decided against their client. In a second column of the table, they are asked to list arguments presented in the "good memo" that support the conclusion that that issue would be decided against their client. Again, students should be able to see where they failed to identify valid points to be made for that position. Following their completion of these tables, students are asked to explain why the writer of the "good memo" chose to include the arguments that the student did not include and why the students did include arguments that the "good memo" excluded. In light of the answer to that question, students are asked to evaluate how they prioritized their time and space: "Did you spend time and space on the most important considerations? What might you have done differently?"

Students are also required to examine whether they had actual legal support for the arguments evaluated. Students are instructed to "annotate" the two tables referenced above with the cases that supported those arguments. Students should recognize that the arguments included in the "good memo" are supported by authority whereas the arguments they chose to present may not be.

After completing these steps for one issue within the memo, students will repeat the process for every other issue within the memo. Ideally, they will discover on their own where their shortfalls reoccur.

\section{Final Assessment Requiring Attribution and Adaptation}

The final section of the Self-Assessment Assignment includes the following instructions:

- Identify, generally, the strengths of your memo.

- Before completing this worksheet, were you aware of the strengths of your memo based on the professor's comments on your first draft or your conference with your professor? ${ }^{96}$ Why or why not?

- Identify, generally, the weaknesses of your memo.

- Identify the strengths of the "good memo."

- Identify the weaknesses of the "good memo."

- If you were to write a third draft of this memo, what would you do that is substantively different from your current draft?

- If you were to write a third draft of this memo, what would you do that is procedurally different from how you went about writing

96. This is another opportunity for the professor to gain information about the effectiveness or his or her conferences with students. See supra note 91. 
your first and second drafts of the memo? (For example, would you allocate more time to check citation or otherwise manage your time differently?)

- List below the top three things that you learned about writing a legal memo from this exercise that you will apply to your work on the next memo assignment.

This line of questioning is designed to re-assess the accuracy of the selfmonitoring. It also requires the student to make attributions to the causes of his successes or failures. This attribution allows the student to adapt, and to revise his strategies for the next legal writing assignment.

\section{E. Other Required Tasks and Unlimited Possibilities}

In addition to the above-described tasks, students are directed to evaluate large-scale organization; they are asked to compare the umbrella sections and headings and subheadings of their own memo and the "good memo." Other tasks require students to analytically compare the Questions Presented, Brief Answers, Statements of Facts, ${ }^{97}$ and Conclusions. Questions are also presented requiring the student to compare the number of quotations in the student's memo and the "good memo" and the difference in the number of citations included in the student's memo and the "good memo," state possible reasons for the disparities, and assess which approach is more effective. ${ }^{98}$ These tasks can be modified and implemented in unlimited number of ways to suit a professor's teaching goals for a specific assignment. $^{99}$

97. For example, the Self-Assessment Assignment instructs students to re-read the Statement of Facts in their own memo and the Statement of Facts in the "good memo," to identify which statement is longer, and then explain why the longer statement is longer. In furtherance of the goal of showing students where they included too many or too few facts, they are to list each fact in their own statement of facts that is not in the "good memo's" Statement of Facts. For each fact that the student included in his memo that is not included in the Statement of Facts of the "good memo," the student is asked to re-examine whether that fact was actually a legally determinative fact and explain why he included it. The objective is, of course, for students to identify where they included facts that were not legally determinative. Students are also asked to do the reverse: to identify facts omitted from their own statement of facts but included in the "good memo's" Statement of Facts, then to explain why they excluded the legally significant fact.

98. Students frequently state that they are impacted by the visual and numerical differences between a memorandum lacking citation and a memo that is well-supported. This exercise helps them to appreciate the impression that is made on a law-trained reader by a written product with scant citation.

99. A copy of a Self-Assessment Assignment will be emailed upon request to jmontiel@faulkner.edu. 


\section{OBJECTIONS ADDRESSED}

\section{A. Is Self-Assessment by Comparative Analysis a Pedagogically-Sound Use of a Sample?}

The use of sample memos in the legal writing curriculum has been criticized. ${ }^{100}$ Admittedly, providing students with a sample memo, alone, is probably not an effective teaching device. Students may or may not read the samples. ${ }^{101}$ In addition, if they do "read" them, students likely will not know what to do with the information they might gain from that reading. ${ }^{102}$ Reading a sample alone does not meaningfully impact the students' learning process. Additionally, there is the danger that some students may view a sample as a "template from which to create all documents of that type."103 Other criticisms are that a sample might suggest that writing is "linear, rather than recursive" or that the writing process is "separate from the thinking process." 104 In short, a sample emphasizes the product more so than the process that is legal writing.

However, wisely using a sample memo can be beneficial. ${ }^{105}$ For example, students need to acclimate to the discourse community into which they are entering, and students can learn to write within the new discourse community - the legal community - by evaluating work product by that community. ${ }^{106}$ That said, the emphasis on the product must be counterbalanced by focus on the process as well, as scholars of legal writing pedagogy have emphasized. ${ }^{107}$ Thus, legal writing professors must be "transparent" when providing samples to students. Students must understand that there is no "fill in the blank method"108 and that what "worked" for the

100. See Coughlin et al., supra note 22, at 391-94 (listing criticisms of the use of samples but concluding that the benefits outweigh the drawbacks).

101. Schwartz, supra note 8, at 472 (noting professor "complaints about students' failure to read the comments we write on exams and papers and learn from them or to take advantage of other learning opportunities we present to them").

102. Without guidance, providing a sample might well undermine a student's self-efficacy. By providing guidance through the Self-Assessment Assignment, though, the student is empowered, rather than defeated by, the exercise, because she learns how she can improve.

103. Coughlin et al., supra note 22, at 392 (quoting Carol McCrehan Parker, Writing Throughout the Curriculum: Why Law Schools Need It and How to Achieve It, 76 NEB. L. REv. 561, 567-68 (1997)).

104. Lysaght \& Lockwood, supra note 40 , at 95.

105. Coughlin et al., supra note 22, at 381-387 (citing many benefits of using samples); Lysaght \& Lockwood, supra note 40, at 96 (stating that the product approach "is not without redeeming qualities," including demonstrating clarity and accuracy, and citing scholars who have noted the need for some emphasis on the final product).

106. Lysaght \& Lockwood, supra note 40, at $98-99$.

107. E.g., id. at 95 ; Felsenburg \& Graham, supra note 19.

108. Felsenburg \& Graham, supra note 19, at 98. 
particular problem that a sample memo addresses may or may not work in analyzing and writing a memo addressing the next legal problem.

The Self-Assessment Assignment is a beneficial way of using a sample memo in the legal writing classroom. ${ }^{109}$ The "good memo" provided to students as part of a Self-Assessment Assignment presents the opportunity to learn about product, but also the opportunity to learn about the process of legal analysis and legal writing. Moreover, because the "good memo" is provided along with a required Self-Assessment Assignment — a tool guiding the student through a formative assessment of their own work in comparison to the "good memo"- the self-regulated learning process is impacted. The Self-Assessment Assignment calls for students to reflect on the "good memo's" analysis and decisions while providing them the opportunity to criticize it. The "good memo" is presented not as an example for students to "go by," 110 but instead requires the students to "critically deconstruct" 111 the "good memo."

According to the Carnegie Report, "students learn best when they can 'reflect on' their knowledge and performance in relation to models supplied by the teacher." 112 The "good memo" proposed in this Article is a sample written by an expert analyzing a problem with which the students are already familiar. The advantages of reviewing a final product are enhanced when the final product shows an expert's analysis of a problem that the students themselves have already analyzed. ${ }^{113}$ In reviewing a sample discussing an issue with which a student is not familiar, the student does not know what authority was available to the writer. He does not know what the authorities

109. For it to serve a useful purpose, the "good memo" provided must, of course, reflect the desired outcomes that the professor has communicated to the students in course materials and in the classroom. See, e.g., Michael Hunter Schwartz, Teaching Law by Design: How Learning Theory and Instructional Design Can Inform and Reform Law Teaching, 38 SAN DIEGO L. REV. 347 (2001) (arguing that law professors fail to identify their learning objectives, provide little congruity between their unstated learning goals and the instructions they provide). For example, if the legal writing professor teaches the CREAC paradigm, her "good memo" should reflect that paradigm, or some variation thereof that the professor has communicated is acceptable. An extraneous benefit of writing the "good memo" is that a professor can adjust her expectations about what final product a student might produce. For example, I have realized that I am much less strict on my students regarding my expectations for how a memo must be structured when I have attempted the memo myself and realized that it is reasonable to organize it in more than one way or that a variation of the CREAC paradigm is necessary. See Karen Mika, Would You Say That to Your Children? Enhancing Learning Through Improved Communication, 48 DUQ. L. REV. 499, 509-10 (2010) (suggesting that professors should keep in mind that they should "revamp" their expectations the longer they teach and to carefully consider whether problems developed are "do-able" by a new law student).

110. See Felsenburg \& Graham, supra note 19, at 97-98.

111. Id. at 97-99.

112. SulLiVAn ET AL., supra note 8, at 61.

113. See Coughlin et al., supra note 22, at 390 (stating that the student reader will "glean about structure and analysis from the sample" if he is familiar with the topic and that "[p]erhaps the strongest response occurs when reviewing students have themselves analyzed the same topic."). 
said and, thus, how the material was organized in relation to the authorities available; he also does not know how the rules were extracted from cases and used by the writer. In contrast, when a student reviews a sample memo that presents analysis of issues with which he is familiar, the student can appreciate, for example, how the writer extracted and synthesized rules from authorities, organized those rules, and applied those rules to the facts given. ${ }^{114}$ In other words, the student can learn by examining the process behind the good memo. Thus, using the "good memo" in conjunction with the Self-Assessment Assignment provides the benefits of using a sample but also teaches students about the process of legal analysis and legal writing.

\section{B. Is "Self"-Assessment Meaningful Assessment?}

One might question whether the self-assessment is a meaningful "formative assessment" given that the professor is not doing the assessing. A student's assessment of his own memo compared to the "good memo" is a formative assessment. There are many sources of formative feedback for law students, and self-assessment is one of them. ${ }^{115}$ First, self-assessment provides feedback during the learning process. ${ }^{116}$ Second, it provides the student with an understanding of the learning outcomes for the course. A student needs to know what "good performance" means. ${ }^{117}$ Providing a "good memo" gives the student a clear picture of the professor's expectations for the particular assignment, which previews for the student the professor's expectations of the course. ${ }^{118}$ It is "the ball" revealed. ${ }^{119}$ It is the standard against which the professor would evaluate the student's memo if the professor himself were evaluating the student's memo. Perhaps more important than the student's understanding of the professor's expectations for the course is the student's understanding of the expectations of any law-

114. Judith B. Tracy, "I See and I Remember; I Do and Understand": Teaching Fundamental Structure in Legal Writing Through the Use of Samples, 21 TOURO L. REV. 297, 316 (2005) (stating that, when a sample is used in this way, a student "will be able to see how the process by which the analysis was developed - through reading and class discussion of the authority—was transformed into a structure which successfully explains the analysis.").

115. Gerald F. Hess, Heads and Hearts: The Teaching and Learning Environment in Law School, $52 \mathrm{~J}$. LEGAL EDUC. 75, 106 (2002).

116. Niedwiecki, supra note 13, at 166 (citing STUCKEY ET AL., supra note 8, at 235-36) ("the most effective way to attack the process" is through formative assessment).

117. Id. at 177 (citing learning theorists David Nicol and Debra Macfarlane Dick, Formative Assessment and Self-Regulated Learning: A Model and Seven Principles of Good Feedback Practice, 31 STUD. HiGHER EDUC. 199, 205 (2006)).

118. The professor must be careful to ensure that there is a "match" between what the student and professor perceive to be the goal of the course or the particular assignment. See id. at 178 (noting the importance that the student's perception of the goals of an assignment or course be the same as the professor's).

119. See Sparrow, supra note 23 (describing advantages of using rubrics to "show the ball" to students). 
trained reader as the law student enters the "legal discourse community." 120 Thus, even though the professor is not providing direct formative assessment in the more traditional sense, Self-Assessment by Comparative Analysis is a formative assessment and, for some, it is an "ideal" formative assessment. ${ }^{121}$

\section{CONCLUSION}

Law professors should implement strategies to improve a student's ability to evaluate his own learning during the learning process. However, increasing the number of formative assessments may be a burden on legal writing professors. And to maximize student learning, it is critical that legal writing professors intervene in the writing process, not merely correct mistakes that have already been made.

Self-Assessment by Comparative Analysis is a method of formative assessment that requires students to self-regulate their learning and relieves the legal writing professor of our typical labor-intensive methodologies. Self-Assessment by Comparative Analysis is less burdensome on the professor than more direct means of formative assessment, such as individual student conferences and detailed critiques. At the same time, it does not negatively impact the legal writing professor's obligation to provide a "rigorous" writing experience in the first year that complies with the ABA's standards. It offers a corresponding benefit to the student by providing the law student a tool with which to self-regulate and make adjustments for future legal writing projects; encouraging the student to reflect on, monitor, and adjust his own process; and requiring him to self-regulate his learning, as he will need to do in practice. Thus, it liberates the professor from our labor-intensive assessment techniques, and empowers the student with the understanding of what it takes to improve.

120. Lysaght \& Lockwood, supra note 40 , at $98-99$. Where a student's focus is on mastering material, he is more likely to succeed than if his focus is simply on the ultimate grade in a course. E.g., Schwartz, supra note 8, at 503 n.205.

121. Niedwiecki, supra note 13, at 183-84 ("Research shows that incorporating self- assessment into the formative assessment process is ideal because it allows the students to focus keenly on the feedback and use it to improve learning."). 